\title{
Comparison of inoculation methods for characterizing relative aggressiveness of two soybean sudden-death syndrome pathogens, Fusarium virguliforme and F. tucumaniae
}

\author{
María Mercedes Scandiani ${ }^{1,2}$, Delma S. Ruberti ${ }^{1}$, Laura M. Giorda ${ }^{3}$, Rosanna N. Pioli ${ }^{2,4}$, Alicia G. Luque ${ }^{2}$, \\ Hebe Bottai ${ }^{5}$, Juan J. Ivancovich ${ }^{5}$, Takayuki Aoki ${ }^{6} \&$ Kerry O'Donnell $^{7}$ \\ ${ }^{1}$ Laboratorio Agrícola Río Paraná, (2930) San Pedro, Argentina; ${ }^{2}$ Centro de Referencia de Micología - CEREMIC, Facultad \\ de Ciencias Bioquímicas y Farmacéuticas, Universidad Nacional de Rosario, Rosario, Argentina; ${ }^{3}$ EEA INTA Manfredi, \\ Manfredi, Argentina; ${ }^{4}$ Cátedra de Fitopatología Facultad de Ciencias Agrarias, Universidad Nacional de Rosario, Campo \\ Experimental Villarino CC 14, 2125 Zavalla, Santa Fe, Argentina; ${ }^{5}$ Área Estadística, Facultad de Ciencias Bioquímicas y \\ Farmacéuticas, Universidad Nacional de Rosario, Rosario, Argentina; ${ }^{2}$ National Institute of Agrobiological Sciences, 2-1-2 \\ Kannondai, Tsukuba, Ibaraki 305-8602, Japan; ${ }^{7}$ Bacterial Foodborne Pathogens and Mycology Research Unit, National \\ Center for Agricultural Utilization Research, USDA Agriculture Research Service, Peoria IL 61604, USA
}

Author for correspondence: María Mercedes Scandiani, e-mail: labagricola@sanpedro.com.ar

\begin{abstract}
Fusarium tucumaniae and $F$. virguliforme are the primary etiological agents of sudden-death syndrome (SDS) of soybean in Argentina and the United States, respectively. Five isolates of $F$. tucumaniae and four isolates of $F$. virguliforme were tested for relative aggressiveness to soybean, using a toothpick inoculation method and two versions of a soil infestation inoculation method. Partially resistant soybean cultivar RA629 and susceptible cultivar A6445RG were inoculated separately with each of the nine isolates. Two experiments for each inoculation method were performed. Analysis of variance identified a significant three-way interaction of soybean cultivar*experiment*SDS pathogen $(P=0.01)$ using the different methods. When the two soil infestation methods were used, $F$. virguliforme was more aggressive than $F$. tucumaniae; however, when using the toothpick method, isolates of $F$. virguliforme and $F$. tucumaniae were equally aggressive. Although all three methods discriminated levels of partial resistance of the genotypes to SDS, results of the present study indicated that soil inoculations with sorghum infested grain represent the best method for evaluating soybean cultivar resistance to SDS. The existence of interactions among the host, pathogen and environmental conditions highlights the need for additional studies to improve the reproducibility of tests for screening soybean germplasm for resistance to SDS.
\end{abstract}

Key words: Glycine max, Argentina, pathogenicity, SDS, United States.

\section{RESUMO}

Comparação de métodos de inoculação para a caracterização de agressividade relativa de dois agentes etiológicos da síndrome da morte súbita de soja, Fusarium tucumaniae e $F$. virguliforme

Fusarium tucumaniae e $F$. virguliforme são agentes etiológicos primários da síndrome da morte súbita (sudden death syndrome SDS) de soja na Argentina e nos Estados Unidos, respectivamente. Cinco isolados de $F$. tucumaniae e quatro isolados de $F$. virguliforme foram testados para agressividade relativa à soja, usando-se o método de ponta de palito de dente e duas versões do método de inoculação com solo infestado. A cultivar de soja parcialmente resistente RA629 e a cultivar suscetível A6445RG foram inoculadas separadamente com cada um dos nove isolados. Dois experimentos para cada método de inoculação foram realizados. A análise da variância identificou uma interação tripla significativa entre cultivar*experimento*patógeno SDS $(\mathrm{P}=0,01)$, usando-se os três métodos. Quando os métodos de infestação de solo foram utilizados, $F$. virguliforme foi mais agressivo que $F$. tucumaniae. Entretanto, quando foi usado o método do palito de dente, isolados de $F$. virguliforme e $F$. tucumaniae foram igualmente agressivos. Embora os três métodos testados tenham discriminado níveis de resistência parcial dos genótipos à SDS, resultados do presente estudo indicam que inoculações no solo com grãos de sorgo infestados representam o melhor método para avaliação de resistência de cultivares de soja à SDS. A existência de interações entre o hospedeiro, patógeno e condições de ambiente destaca a necessidade de estudos adicionais para melhorar a reprodutibilidade de testes de seleção de germoplasmas de soja para resistência à SDS.

Palavras-chave: Glycine max, Argentina, patogenicidade, SDS, Estados Unidos.

\section{INTRODUCTION}

Sudden death syndrome (SDS) of soybean (Glycine $\max ($ L.) Merr.) has been reported in North America (Rupe,
1989) and several South American countries (Nakajima et al., 1996; Wrather et al., 1997; O’Donnell et al., 2010). Prior to the recognition that four closely related Fusarium spp. can induce soybean SDS, based on detailed morphological 
and molecular phylogenetic analyses (Aoki et al., 2003, 2005), the SDS pathogens were typically reported in the literature as Fusarium solani f. sp. glycines. However, it is now recognized that SDS is caused by $F$. virguliforme within the U.S. and Canada, whereas in Argentina it is caused by at least four Fusarium species: F. tucumaniae, F. virguliforme, F. brasiliense, and an undescribed Fusarium spp. (Aoki et al., 2005; O'Donnell et al., 2010). Fusarium tucumaniae is the dominant species in Argentina, comprising over threequarters of the SDS isolates genotyped, with $F$. virguliforme forming a comparatively small percentage of the SDS pathogens sampled (O'Donnell et al., 2010). Results of the latter survey revealed that these two pathogens both occur in the same soybean core-producing provinces of Buenos Aires and Santa Fe.

SDS foliar symptoms are thought to be induced by a low molecular weight toxin (Jin et al., 1996) and include mottling of leaves on the upper part of the plant, interveinal chlorosis, necrosis and defoliation (Hartman et al., 1999). Additional symptoms include root rot, crown rot, vascular discoloration of the stem, pod abortion and red coloration on the basal stems, although the pith remains white. In addition, blue to yellow sporulation of the pathogen on the taproots is frequently observed.

Because soybean germplasm exhibits various levels of resistance to $F$. virguliforme, increasing resistance to $F$. virguliforme and $F$. tucumaniae is an important objective of soybean cultivar development. Screening for SDS resistance has been conducted under field conditions, both in natural (Rupe, 1991, 1995; Wrather et al., 1995) and artificially infested soil (Melgar et al., 1994; Scherm \& Yang, 1996). Even when cultivars are screened in artificially infested soil, disease incidence is unpredictable due to the sensitivity of symptomology to environmental factors (Schuerger \& Mitchell, 1993; Rupe et al., 1996; Farias Neto et al, 2008). Methods for assessing aggressiveness (i.e., amount of disease induced) in greenhouse studies include using soil infestation by growing the pathogen on sorghum grain (Hartman et al., 1997, 1999; Huang \& Hartman, 1998; Cho et al., 2001; Rupe et al., 2001; Mueller et al., 2002a, 2002b, 2003; Aoki et al., 2005; Farias Neto et al., 2008; Franco et al., 2009), oat seeds (Scherm \& Yang, 1996), sand-cornmeal (Melgar et al., 1994; Gray \& Achenbach, 1996; Gray et al., 1999; Njiti et al., 2001), culture filtrates (Jin et al., 1996; Li et al., 1999), inoculation via a toothpick method (Melgar \& Roy, 1994; Arruda et al., 2005), colonized agar plugs (Rupe, 1989), a detached leaf method (Franco et al., 2009) and conidial suspensions (Rupe et al., 1996; Njiti et al., 2001). Development of an accurate disease scoring method for screening resistance to these pathogens, in a rapid and uniform way in the greenhouse, is crucial for developing soybean cultivars with broadbased resistance to the SDS pathogens. Although various inoculation methods for testing relative aggressiveness of $F$. virguliforme isolates and evaluating soybean response to the pathogen within a greenhouse have been reported, little information is available regarding direct comparisons of the aggressiveness of $F$. virguliforme and $F$. tucumaniae isolates in soybean. Thus, the present study was initiated to assess the relative aggressiveness of $F$. tucumaniae and $F$. virguliforme isolates on partially resistant and susceptible soybean cultivars, using three greenhouse inoculation methods.

\section{MATERIALS AND METHODS}

\section{Fungal isolates}

SDS symptomatic plants were sampled from different fields in the provinces of Buenos Aires and Santa Fe, the core soybean-production areas of Argentina, in 2002 and 2003. As soon as plants were removed from the ground, the roots were cleaned, wrapped separately in moist newspaper, and then incubated at $10^{\circ} \mathrm{C}$ in the dark to promote sporulation. Plants were examined macroscopically each day for signs of sporulation. To confirm that the fungus was a Fusarium spp. causing SDS, blue, green and yellowish conidial masses were mounted in water on microscope slides and examined microscopically (Roy, 1997). Isolates of SDS-causing Fusarium spp. were obtained using potato dextrose agar (Laboratorios Britania S.A.) amended with streptomycin, (100 mg/L; PDAS) (Singleton et al., 1993). For this purpose macroconidia morphologically similar to the SDS-causing Fusarium spp. were transferred to sterilized distilled water on a sterile microscope slide and then streaked onto PDAS plates, which were incubated at $25^{\circ} \mathrm{C}$ in the dark. To exclude fast growing non-SDS members of the $F$. solani species complex, colony growth rate was recorded and only isolates with a colony diameter of $\leq 2 \mathrm{~cm}$ after 4 days were retained (Scandiani et al., 2003). All of the isolates were pure cultures obtained by the dilution plate method.

Isolates were identified using morphology and molecular phylogenetics (Scandiani et al., 2003, 2004; Aoki et al., 2005; O’Donnell et al., 2010) (Table 1). Based on these analyses, five isolates of F. tucumaniae NRRL 34546, F. tucumaniae NRRL 34547, F. tucumaniae NRRL 34548, F. tucumaniae NRRL 34549 and F. tucumaniae NRRL 34550 , and three isolates of $F$. virguliforme NRRL 34551, $F$. virguliforme NRRL 34552, and $F$. virguliforme NRRL 34553 , were selected for the aggressiveness experiment. Isolate 171 of $F$. virguliforme, kindly provided by Dr. John C. Rupe (University of Arkansas), was used as a positive control for pathogenicity to soybean.

\section{Inoculum production}

Soil infestation. Inoculum of the eight isolates, plus strain 171 , was prepared by soaking $200 \mathrm{~g}$ of sorghum grain in 400 $\mathrm{mL}$ distilled water in a 1-liter Erlenmeyer flask overnight. Excess water was decanted, after which the grain was autoclaved for $60 \mathrm{~min}$ at $121^{\circ} \mathrm{C}$ on two consecutive days (Huang \& Hartman, 1998; Mueller et al., 2003). Once cooled, each sterilized sorghum grain-containing flask was 
Comparison of inoculation methods for characterizing relative aggressiveness...

TABLE 1 - Source of Fusarium virguliforme and F. tucumaniae isolates tested for relative aggressiveness on two soybean cultivars using infested soil and toothpick inoculation methods

\begin{tabular}{|c|c|c|c|c|}
\hline Species & NRRL $^{a}$ & Geographic origin & Host & Equivalent number ${ }^{\mathrm{b}}$ \\
\hline Fusarium virguliforme & 34551 & Argentina, Buenos Aires, San Pedro & Glycine max & CCC $-101-03=\mathrm{LP}$ \\
\hline Fusarium virguliforme & 34552 & Argentina, Santa Fe, Serodino & Glycine $\max$ & $\mathrm{CCC}-102-03=\mathrm{M} 5$ \\
\hline Fusarium virguliforme & 34553 & Argentina, Santa Fe, Serodino & Glycine max & CCC $-103-03=\mathrm{M} 6$ \\
\hline Fusarium virguliforme & - & USA, Arkansas & Glycine max & 171 \\
\hline Fusarium tucumaniae & 34546 & Argentina, Buenos Aires, Arrecifes & Glycine max & $\mathrm{CCC}-125-02=3-2$ \\
\hline Fusarium tucumaniae & 34547 & Argentina, Santa Fe, Las Parejas & Glycine max & CCC $12602=81$ \\
\hline Fusarium tucumaniae & 34548 & Argentina, Santa Fe, Las Parejas & Glycine max & $\mathrm{CCC}-127-02=8-2$ \\
\hline Fusarium tucumaniae & 34549 & $\begin{array}{l}\text { Argentina, Buenos Aires, Pérez } \\
\text { Millán }\end{array}$ & Glycine $\max$ & $\mathrm{CCC}-129-02=\mathrm{Wk}-2$ \\
\hline Fusarium tucumaniae & 34550 & Argentina, Santa Fe, Pujato & Glycine max & CCC $-128-02=$ Pujato \\
\hline
\end{tabular}

${ }^{a}$ NRRL, Agriculture Research Service Culture Collection, National Center for Agricultural Utilization Research, USDA/ARS, Peoria, IL, USA

${ }^{b}$ CCC, CEREMIC Culture Collection, Centro de Referencia de Micología, Facultad de Ciencias Bioquímicas y Farmacéuticas, UNR, Rosario, Argentina.

inoculated with 5 mycelial plugs ( $5 \mathrm{~mm}$ in diameter) from a potato dextrose agar culture of one of the nine SDS isolates. Cultures were incubated in complete darkness for 15 days at $25^{\circ} \mathrm{C}$.

Toothpick method. To obtain inoculum for the aggressiveness experiment using the toothpick method, $12 \mathrm{~mm}$ long toothpicks were boiled for $15 \mathrm{~min}$ in three consecutive changes of distilled water, dried and placed, sharpened end up, in holes made in a $90 \mathrm{~mm}$ diameter filter paper. The toothpicks were then placed in a petri dish and autoclaved for $20 \mathrm{~min}$ at $121^{\circ} \mathrm{C}$. Twenty $\mathrm{mL}$ of melted PDAS was added to each toothpick-containing petri dish. Once solidified, the PDAS plates were inoculated with five mycelial plugs $(6 \mathrm{~mm}$ in diameter) of one of the SDS isolates and then were incubated at $25^{\circ} \mathrm{C}$ in the dark for 15 days.

Soybean cultivars. Two commercial soybean cultivars were used in the aggressiveness experiment: RA629, derived from the cultivar Forrest (Huang \& Hartman, 1998) which is partially resistant to SDS, and A6445RG, previously determined to be susceptible to SDS (Scandiani et al., 2004; Lenzi et al., 2005). Both cultivars were of the same maturity group and had similar growth habit.

\section{Inoculation methods}

Soil infestation method. Soil used in this study was previously treated with methyl bromide (MB) (Melgar et al., 1994). The two soil infestation inoculation methods differed by the type of container used: plastic pots, $8 \times 11$ $\mathrm{cm}$, filled with $150 \mathrm{~g}$ of soil or tray containers in which each small pot was filled with 70 grams of soil $(4 \times 5.5 \mathrm{~cm})$. Soil was infested by placing colonized sorghum grain below soybean seeds at planting. Three grams of infested sorghum grain was distributed as a layer in each pot and then covered with a 2-cm layer of soil. Next, three soybean seeds were planted in each pot and one in each pot of the tray container, and were covered with $2 \mathrm{~cm}$ of soil.

Toothpick method. The inoculation technique used was a modification of the toothpick method reported by Keeling (1982). Twenty five seeds were sown in disinfested soil in $18-\mathrm{cm}$ diameter plastic pots and subsequently thinned to twenty seedlings per pot. Seedlings were inoculated 7 days after planting by inserting a toothpick tip overgrown with mycelia of one of the isolates in each hypocotyl $1 \mathrm{~cm}$ below the cotyledons. Seedlings were placed in a moist chamber and incubated for 5 days prior to being transferred to a greenhouse.

The experiments were performed during spring 2003 (Experiment 1) and replicated in early summer 2003 (Experiment 2). The experiments were conducted at $28 \pm 3^{\circ} \mathrm{C}$ with natural photoperiod and natural light intensity and terminated 30 days after inoculation. Soil was watered to saturation after planting and maintained at near water-holding capacity. Noninfested sorghum grains and toothpicks were used as negative controls, for the soil infestation and toothpick inoculation experiments, respectively.

\section{Disease ratings}

Soil infestation method. Foliar disease severity was rated 30 days after sowing. Plant assessments were made using a foliar disease severity scale, where $1=$ no symptoms $(0 \%$ foliage affected); 2 = slight symptom development with mottling and mosaic on leaves (1-20\% foliage affected); 3 = moderate symptom development with interveinal chlorosis and necrosis on foliage (21-50\% foliage affected); $4=$ heavy symptom development with interveinal chlorosis and necrosis $(51-80 \%$ foliage affected); and $5=$ severe 
M.M. Scandiani et al.

interveinal chlorosis and necrosis $(81-100 \%$ foliage affected) (Huang \& Hartman, 1998).

Toothpick method. The incidence of plants with stem and foliar disease symptoms was rated on a weekly basis. From the multiple disease incidence ratings, the area under disease progress curve (AUDPCi) was calculated.

Experimental design and data analysis. For the soil infestation methods, for a given experiment, there were 3 replications of three seeds in four plastic pots (a total of thirty six seeds), and 3 replications of one seed in each of 12 small pots of the tray container (a total of thirty six seeds) were planted for each combination of cultivar and pathogen. To compare foliar disease severity ratings, the scale was converted to percentages using the midpoint value where $1=0 \%, 2=10 \%, 3=35 \%, 4=65 \%$, and $5=$ $90 \%$ (Huang \& Hartman, 1998). For the toothpick method, there were two replications of 25 seeds, planted per each combination of cultivar and pathogen and, after emergence, thinned to twenty plants (a total of 40 seedlings). The effects of cultivar, fungal species, isolate (nested within fungal species) (fixed effects), experiment (random effect) and their interactions were evaluated for analysis of variance (mixed model ANOVA). Means were separated according to Fisher's protected least significance difference (LSD) at 5\% probability, using the R Development Core Team (2008).

\section{RESULTS}

All isolates of $F$. virguliforme and $F$. tucumaniae tested produced typical SDS foliar symptoms, which included mottling, mosaic, interveinal chlorosis and necrosis. Seedlings inoculated via the toothpick method developed a necrotic lesion around the point of inoculation, and mosaic on the upper leaves 10 days after inoculation. With the soil infestation method, the first foliar symptoms were observed 10 days after inoculation in older leaves as chlorotic spots followed by interveinal chlorosis.

Inoculation via soil infestation method in plastic pots Analysis of variance identified a significant threeway interaction of soybean cultivar*experiment*fungal species $(P=0.055)$ (Table 2$)$. In both experiments $F$. virguliforme was more aggressive than $F$. tucumaniae and soybean cultivar A6445RG was more susceptible than RA629. In both experiments, $F$. virguliforme strain NRRL 34551 was the most aggressive isolate on cultivar RA629, followed by $F$. virguliforme strains NRRL 34552 and 171, which were equally aggressive, and $F$. virguliforme NRRL 34553, which was the least aggressive. By way of contrast, $F$. virguliforme NRRL 34552 was the most aggressive isolate on cultivar A6445RG in both experiments, followed by F. virguliforme isolates NRRL 34551 and 171 which were equally aggressive, and $F$. virguliforme NRRL 34553, which was the least aggressive. In experiment 1 , differences in aggressiveness among the $F$. tucumaniae isolates were observed. F. tucumaniae NRRL 34546 was the most aggressive isolate of this species on cultivar RA629; however, F. tucumaniae NRRL 34548 was the most aggressive on cultivar A6445RG. In experiment 2, no significant differences in aggressiveness among the $F$. tucumaniae isolates were observed.

TABLE 2 - Percent mean foliar disease severity on soybean cultivars RA629 (resistant) and A6445RG (susceptible) in experiments 1 and 2 inoculated with Fusarium virguliforme or F. tucumaniae using infested soil in pots

\begin{tabular}{|c|c|c|c|c|}
\hline & \multicolumn{4}{|c|}{ Mean foliar severity* } \\
\hline & \multicolumn{2}{|c|}{ Experiment 1} & \multicolumn{2}{|c|}{ Experiment 2} \\
\hline & RA629 & A6445RG & RA629 & A6445RG \\
\hline \multicolumn{5}{|c|}{ Fusarium virguliforme } \\
\hline 171 & $23.5 \mathrm{~b}$ & $43.6 \mathrm{~b}$ & $31.8 \mathrm{~b}$ & $50.1 \mathrm{~b}$ \\
\hline NRRL 34551 & $35.1 \mathrm{a}$ & $46.3 \mathrm{~b}$ & $40.4 \mathrm{a}$ & $49.3 \mathrm{~b}$ \\
\hline NRRL 34552 & $26.5 \mathrm{~b}$ & $78.9 \mathrm{a}$ & $33.1 \mathrm{~b}$ & $57.4 \mathrm{a}$ \\
\hline NRRL 34553 & $11.5 \mathrm{c}$ & $22.2 \mathrm{c}$ & $28.3 \mathrm{c}$ & $35.8 \mathrm{c}$ \\
\hline \multicolumn{5}{|c|}{ Fusarium tucumaniae } \\
\hline NRRL 34546 & $14.0 \mathrm{a}$ & $21.3 \mathrm{~b}$ & $4.6 \mathrm{a}$ & $11.0 \mathrm{a}$ \\
\hline NRRL 34547 & $4.7 \mathrm{~b}$ & $5.4 \mathrm{c}$ & $3.5 \mathrm{a}$ & $11.5 \mathrm{a}$ \\
\hline NRRL 34548 & $5.0 \mathrm{~b}$ & $27.1 \mathrm{a}$ & $2.9 \mathrm{a}$ & $12.5 \mathrm{a}$ \\
\hline NRRL 34549 & $6.3 \mathrm{~b}$ & $20.8 \mathrm{~b}$ & $4.4 \mathrm{a}$ & $11.0 \mathrm{a}$ \\
\hline NRRL 34550 & $2.2 \mathrm{~b}$ & $2.2 \mathrm{c}$ & $7.9 \mathrm{a}$ & $12.9 \mathrm{a}$ \\
\hline
\end{tabular}

*Mean foliar disease severity ratings of 36 plants for each isolate and two soybean cultivars were based on a scale of 1 to 5 where, $1=$ no symptoms $(0 \%$ foliage affected $) ; 2=$ slight symptom development with mottling and mosaic on leaves $(1-20 \%$ foliage affected $) ; 3=$ moderate symptom development with interveinal chlorosis and necrosis on foliage (21-50\% foliage affected); $4=$ heavy symptom development with interveinal chlorosis and necrosis (51-80\% foliage affected); and $5=$ severe interveinal chlorosis and necrosis (81-100\% foliage affected) (12). To compare foliar disease severity ratings, data were converted to percent using the midpoint value where $1=0 \%, 2=10 \%, 3=35 \%, 4=65 \%$, and $5=90 \%$ (12). For the same experiment, cultivar and species, averages followed by the same letter do not differ according to the test. 


\section{Inoculation via soil infestation method in tray containers}

Analysis of variance identified a significant threeway interaction of soybean cultivar*experiment*fungal species $(P=0.01)$ (Table 3$)$. In both experiments, $F$. virguliforme was more aggressive than $F$. tucumaniae and soybean cultivar A6445RG was more susceptible than RA629. In experiment 1, F. virguliforme isolate 171 and NRRL 34553 were the most aggressive isolates on cultivar A6445RG, followed by NRRL 34551 and NRRL 34552 , which were equally aggressive. In experiment 2 , $F$. virguliforme strain 171 was the most aggressive on cultivar A6445RG, followed by $F$. virguliforme NRRL 34551 and 34553 , which were equally aggressive, with F. virguliforme NRRL 34552 being the least aggressive isolate tested. There were no significant differences in aggressiveness among the isolates of $F$. tucumaniae tested.

\section{Inoculation via toothpick method}

Analysis of variance identified a significant threeway interaction of soybean cultivar*experiment*fungal species $(P=0.01)$ (Table 4$)$. In both experiments, soybean cultivar A6445RG was more susceptible than RA629 to both SDS pathogens $(P<0.0001)$, and no significant effect of the isolate within each fungal species was observed. In experiment $1, F$. virguliforme was more aggressive than F. tucumaniae on cultivar A6445RG; no differences were observed between the two SDS pathogens on RA629. In experiment 2, F. tucumaniae was more aggressive than $F$. virguliforme on both soybean cultivars.

\section{DISCUSSION}

The five isolates of F. tucumaniae and the four isolates of $F$. virguliforme tested all induced symptoms typical of

TABLE 3 - Percent mean foliar disease severity of soybean cultivars RA629 (resistant) and A6445RG (susceptible) in experiments 1 and 2 inoculated with Fusarium virguliforme or F. tucumaniae using infested soil in tray containers

\begin{tabular}{|c|c|c|c|c|}
\hline & \multicolumn{4}{|c|}{ Mean foliar severity* } \\
\hline & \multicolumn{2}{|c|}{ Experiment 1} & \multicolumn{2}{|c|}{ Experiment 2} \\
\hline & RA629 & A6445RG & RA629 & A6445RG \\
\hline \multicolumn{5}{|c|}{ Fusarium virguliforme } \\
\hline 171 & $31.1 \mathrm{~b}$ & $65.1 \mathrm{a}$ & $26.5 \mathrm{~b}$ & $73.1 \mathrm{a}$ \\
\hline NRRL 34551 & $30.3 \mathrm{~b}$ & $48.8 \mathrm{~b}$ & $26.1 \mathrm{~b}$ & $62.1 \mathrm{~b}$ \\
\hline NRRL 34552 & $28.9 \mathrm{~b}$ & $46.8 \mathrm{~b}$ & $27.2 \mathrm{~b}$ & $53.2 \mathrm{c}$ \\
\hline NRRL 34553 & $48.1 \mathrm{a}$ & $59.0 \mathrm{a}$ & $45.3 \mathrm{a}$ & $61.0 \mathrm{~b}$ \\
\hline \multicolumn{5}{|c|}{ Fusarium tucumaniae } \\
\hline NRRL 34546 & $2.6 \mathrm{a}$ & $4.7 \mathrm{a}$ & $3.8 \mathrm{a}$ & $10.3 \mathrm{a}$ \\
\hline NRRL 34547 & $0.8 \mathrm{a}$ & $1.7 \mathrm{a}$ & $5.8 \mathrm{a}$ & $9.9 \mathrm{a}$ \\
\hline NRRL 34548 & $0.8 \mathrm{a}$ & $1.7 \mathrm{a}$ & $5.1 \mathrm{a}$ & $9.2 \mathrm{a}$ \\
\hline NRRL 34549 & $1.9 \mathrm{a}$ & $3.3 \mathrm{a}$ & $6.4 \mathrm{a}$ & $10.8 \mathrm{a}$ \\
\hline NRRL 34550 & $0.0 \mathrm{a}$ & $3.3 \mathrm{a}$ & $6.4 \mathrm{a}$ & $10.4 \mathrm{a}$ \\
\hline
\end{tabular}

*Mean foliar disease severity ratings of 3 groups of 12 plants for each isolate and soybean cultivar were based on a scale of 1 to 5 where, $1=$ no symptoms $(0 \%$ foliage affected); 2 = slight symptom development with mottling and mosaic on leaves $(1-20 \%$ foliage affected); $3=$ moderate symptom development with interveinal chlorosis and necrosis on foliage (21-50\% foliage affected); 4 = heavy symptom development with interveinal chlorosis and necrosis (51-80\% foliage affected); and $5=$ severe interveinal chlorosis and necrosis ( $81-100 \%$ foliage affected) (12). To compare foliar disease severity ratings, data were converted to percent using the midpoint value where $1=0 \%, 2=10 \%, 3=35 \%, 4=65 \%$, and $5=90 \%$ (12). For the same experiment, cultivar and species, averages followed by the same letter do not differ according to the test.

TABLE 4 - Area under disease progress curve of incidence (AUDPCi) caused by Fusarium virguliforme and F. tucumaniae on two soybean cultivars (RA629, resistant, and A6445RG, susceptible) by the toothpick inoculation method in experiments 1 and 2

\begin{tabular}{|c|c|c|c|c|}
\hline & \multicolumn{4}{|c|}{ AUDPCi* } \\
\hline & \multicolumn{2}{|c|}{ Experiment 1} & \multicolumn{2}{|c|}{ Experiment 2} \\
\hline & RA629 & A6445RG & RA629 & A6445RG \\
\hline Fusarium virguliforme & $603.12 \mathrm{a}$ & $2084.06 \mathrm{a}$ & $935.31 \mathrm{~b}$ & $1428.12 \mathrm{~b}$ \\
\hline Fusarium tucumaniae & $791.25 \mathrm{a}$ & $1810.75 \mathrm{~b}$ & $1218.00 \mathrm{a}$ & $1905.25 \mathrm{a}$ \\
\hline
\end{tabular}

*Incidence of two groups of 20 plants with stem and foliar disease symptoms was rated weekly for each isolate and soybean cultivar. For multiple disease incidence ratings, area under disease progress curve of incidence (AUDPCi) was calculated. For the same experiment, cultivar and species, averages followed by the same letter do not differ according to the test. 
SDS in our greenhouse aggressiveness experiment, using the toothpick method and with both variations of the soil infestation inoculation method. Our results found that $F$. virguliforme was more aggressive than $F$. tucumaniae using the soil infestation methods, but in one of the two experiments, F. tucumaniae appeared to be more aggressive than $F$. virguliforme when inoculated using the toothpick method. Although foliar symptoms are theorized to be induced by translocation into the leaves of a low molecular weight toxin produced on or in colonized roots ( $\mathrm{Li}$ et al., 2009), our results suggest that a toxin may have been produced from the inoculation point on the stems using the toothpick method. Plants inoculated by the toothpick method exhibited symptoms on the hypocotyls that ranged from an external lesion up to $1 \mathrm{~cm}$ in diameter at the point of inoculation to larger lesions with mottling and mosaic on leaves, interveinal chlorosis and necrosis of foliage, and plant death. Even though the toothpick method artificially breaks down stem resistance barriers (Hutcheson, 1998), our results indicated that it might be useful for predicting shoot resistance, and for monitoring toxin production and its translocation in soybean plants. Similar to Melgar and Roy (1994), and Arruda et al. (2005), we were able to distinguish levels of partial resistance of the two soybean genotypes by using the toothpick method. Although the toothpick inoculation method was previously scored by measuring the stem length lesion (Melgar \& Roy, 1994; Arruda et al., 2005), disease severity was able to score for both stem lesion and foliar symptoms development in the current study. Using the toothpick method, F. virguliforme was more aggressive than $F$. tucumaniae in experiment 1 , while in experiment 2, F. tucumaniae was more aggressive than $F$. virguliforme. Although the underlying basis for this difference is unknown, one hypothesis might be due to sensitivity of symptomology to subtle differences in the environmental conditions when the experiments were conducted in the spring and early summer (Schuerger \& Mitchell, 1993; Rupe et al., 1996; Farias Neto et al, 2008).

Regardless of the inoculation method used, most studies have reported a difference in aggressiveness of F. virguliforme isolates (Achenbach et al., 1996; Gray \& Achenbach, 1996; Cho et al., 2001; Rupe et al., 2001; Mueller et al., 2002a; Li et al., 2009). It is worth mentioning that disease severity has been evaluated using culture filtrates of $F$. virguliforme as well as a cut-seedling assay (Jin et al., 1996; Huang \& Hartman, 1998; Li et al., 1999). Surprisingly, culture filtrates induced foliar symptoms typical of SDS and yielded a disease severity ranking comparable to a greenhouse experiment using infested sorghum and to the results we obtained using the toothpick method.

As previously shown, results of the present study indicated that soil inoculations with sorghum infested grain represented the best method for evaluating soybean cultivar resistance to SDS, as the colonization-infection process appears to more closely replicate what happens under natural field conditions (Juliatti et al., 2004). This method induced typical SDS symptoms in all parts of the plant, including root-rot, necrosis at the base of the stem, interveinal chlorosis and necrosis in the shoot. In the present study, the first foliar symptoms were observed 10 days after inoculation in the older leaves and included chlorotic spots followed by interveinal chlorosis. Results of the present study clearly establish that soil inoculations with sorghum infested grain, both in pots and containers, are effective for pathogenic characterization of $F$. tucumaniae and $F$. virguliforme. It is important to note, however, that artificial inoculations via soil infestation performed in winter on the highly susceptible soybean cv. Pioneer 9492RR failed to detect differences in aggressiveness in the soybean SDS pathogens (Aoki et al., 2005). There was also considerable variability in foliar symptoms in our trials run at different periods of the year. For example, aggressiveness of $F$. tucumaniae isolates was higher in greenhouse inoculations during the winter, and was comparable to that caused by $F$. virguliforme isolates, in contrast to trials run during spring. We attribute this difference to poor vegetative development of the host during the winter, presumably due to the shorter natural photoperiod and low effective heliophany. Because the experiments were performed during different seasons, variation in photoperiod and heliophany might have been the most important environmental factor that affected foliar symptoms. In relation to the infection process of $F$. virguliforme and the expression of SDS foliar symptoms, there exist effective and ineffective zones of infection in the roots (Navi \& Yang, 2008). Another consideration is that infection by $F$. virguliforme on the lower portion of germinating soybean roots is more likely to result in SDS foliar symptoms than the upper or middle portions of the root during infection (Zaccaron et al., 2010).

In the present study, a significant interaction between experiment and replicates was detected, due to the interaction between the host and pathogen with the environment. Results of previous studies performed in winter demonstrated that soil infested with SDS-causing fungal species reduced plant height in greenhouse conditions (Aoki et al., 2005). Disease ratings made by determining shoot length and plant weight have been reported as a useful tool for comparing aggressiveness of $F$. virguliforme isolates ( $\mathrm{Li}$ et al., 2009). In this current study there was no reduction in plant height and weight when trials were conducted in the spring and summer with either method. Previous research has observed differential reactions of the host based on the method of inoculation used. Achenbach et al. (1996) evaluated cv. Spencer using $F$. virguliforme isolates FSA-1 and NRRL 22823 (Aoki et al., 2003) and determined that they did not cause foliar SDS symptoms when soil inoculations were employed. Interestingly, these same isolates had previously been described by other authors as inducing SDS symptoms using the toothpick method (Achenbach et al., 1996). In addition, Njiti et al. (2001) evaluated aggressiveness of $F$. 
Comparison of inoculation methods for characterizing relative aggressiveness...

virguliforme isolate ST90 using different concentrations of a macroconidial suspension on different lines of soybean and identified a significant interaction between the concentration of inoculum x experiment. Jin et al. (1996) also observed that $F$. virguliforme Mont-1 isolate, inoculated by filtering the pathogen over cv. Asgrow 3427, produced a foliar severity of 4.3 in the first assay, but only 2.5 in the second experiment, based on a rating scale from of 1 to 5 . Although inoculations of $F$. tucumaniae by the detached leaf method were unable to discriminate soybean cultivar resistance to SDS, the soil infested (Franco et al., 2009) and toothpick methods (Arruda et al., 2005) have been shown to be useful for discriminating levels of aggressiveness of this SDS pathogen.

Research is needed to elucidate the infection process of the SDS and bean root-rot fusaria (O'Donnell et al., 2010). It may be essential to determine whether toxins contribute to virulence and how environmental conditions influence the expression of foliar symptoms. Inter-experiment variability, which contributes to significant interactions, is influenced by various factors that affect both the host and the pathogen, such as light, temperature, soil, soil moisture, inoculum concentration and changes in aggressiveness (Scherm \& Yang, 1996; Njiti et al., 2001). In addition, mucilage production by macroconidia of $F$. cuneirostrum (reported as $F$. solani f. sp. phaseoli) has been shown to contribute to adhesion of conidia to mung bean roots during infection (Schuerger \& Mitchell, 1993; Schuerger et al., 1993). These authors also elucidated the importance of the carbon source during colonization and infection process by germinating macroconidia.

In summary, the aggressiveness of F. tucumaniae and F. virguliforme to soybean, the dominant SDS pathogens respectively in Argentina and the U.S., was assessed in the present study for the first time using different inoculations methods. The existence of interactions among the host, pathogen and environmental conditions highlights the need for additional studies to improve the reproducibility of tests for screening soybean germplasm for resistance to SDS. In order to assess soybean varieties and lines in development for resistance to SDS, as well as commercial varieties currently in production, the relative aggressiveness of all four SDScausing Fusarium species should be characterized further. To this end, these studies should focus on elucidating the spectrum of shoot and root symptoms caused by each of the SDS-causing pathogens in greenhouse and field experiments.

\section{ACKNOWLEDGEMENTS}

The mention of trade products does not imply that they are endorsed or recommended by the U. S. Department of Agriculture over other firms or similar products not mentioned. We thank Leila Costamilan for her assistance with the preparation of the abstract in Portuguese.

\section{REFERENCES}

Achenbach LA, Patrick J, Gray L (1996) Use of RAPD markers as a diagnostic tool for the identification of Fusarium solani isolates that cause soybean sudden death syndrome. Plant Disease 80:12281232.

Aoki T, O'Donnell K, Homma Y, Lattanzi A (2003) Sudden death syndrome of soybean is caused by two morphologically and phylogenetically distinct species within the Fusarium solani species complex, F. virguliforme in North America and F. tucumaniae in South America. Mycologia 95:660-668.

Aoki T, O’Donnell K, Scandiani MM (2005) Sudden death syndrome of soybean in South America is caused by four species of Fusarium: Fusarium brasiliense sp. nov., F. cuneirostrum sp. nov., F. tucumaniae and $F$. virguliforme. Mycoscience 46:162-183.

Arruda GMT, Miller RNG, Ferreira MASV, Café-Filho AC (2005) Morphological and molecular characterization of the suddendeath syndrome pathogen of soybean in Brazil. Plant Pathology 54:53-65.

Cho JH, Rupe JC, Cummings MS, Gbur EE (2001) Isolation and identification of Fusarium solani f. sp. glycines from soil on modified Nash and Snyder's medium. Plant Disease 85:256-260.

Farias Neto A, Schimidt M, Hartman GL, Li S, Diers BW (2008) Inoculation methods under greenhouse conditions for evaluating soybean resistance to sudden death syndrome. Pesquisa Agropecuária Brasileira 43:1475-1482.

Franco HBJ, Centurion MPPC, Barbosa JC (2009) Estudo de metodos de inoculação para a avaliação de cultivares de soja a Fusarium tucumaniae. Summa Phytopathologica 35:32-38.

Gray LE, Achenbach LA (1996) Severity of foliar symptoms and root and crown rot of soybean inoculated with various isolates and inoculum rates of Fusarium solani. Plant Disease 80:1197-1199.

Gray LE, Achenbach LA, Duff RJ, Lightfoot D (1999) Pathogenicity of Fusarium solani $\mathrm{f}$. sp. glycines isolates on soybean and green bean plants. Journal of Phytopathology 147:281-284.

Hartman GL, Huang YH, Nelson RL, Noel GR (1997) Germplasm evaluation of Glycine max for resistance to Fusarium solani, the causal organism of sudden death syndrome. Plant Disease 81:515518 .

Hartman GL, Sinclair JC, Rupe JC (1999) Compendium of Soybean Diseases. 4th Ed. Saint Paul MN. APS Press.

Huang YH, Hartman GL (1998) Reaction of selected soybean genotypes to isolates of Fusarium solani f. sp. glycines and their culture filtrates. Plant Disease 82:999-1002.

Hutcheson SW (1998) Current concepts of active defense in plants. Annual Review of Phytopathology 36:59-90.

Jin H, Hartman GL, Nickell CD, Widholm JM (1996) Phytotoxicity of culture filtrate from Fusarium solani, the causal agent of soybean sudden death syndrome. Plant Disease 80:922-927.

Juliatti FC, Castillo Polizel A, Juliatti FC (2004) Manejo integrado de doenças na cultura da soja. Uberlandia MG. Editora Universidade Federal de Uberlândia MG.

Keeling BL (1982)A seedling test for resistance to soybean stem canker caused by Diaporthe phaseolorum var. caulivora. Phytopathology 72:807-809. 
Lenzi L, Fuentes F, Gilli J, Masiero B (2005) Evaluación a campo del comportamiento de cultivares comerciales de Soja frente al Síndrome de la Muerte Súbita. Soja actualización 2005. Información para extensión $n^{\circ} 97$ EEA Marcos Juárez INTA.

Li S, Hartman GL, Widholm JM (1999) Viability staining of soybean suspension-cultured cells and a seedling stem cutting assay to evaluate phytotoxicity of Fusarium solani f. sp. glycines culture filtrates. Plant Cell Reporter 18:375-380.

Li S, Hartman GL, Chen Y (2009) Evaluation of aggressiveness of Fusarium virguliforme isolates that cause soybean sudden death syndrome. Journal of Plant Pathology 91:77-86.

Melgar J, Roy KW (1994) Soybean sudden death syndrome: cultivar reactions to inoculation in a controlled environment and host range and virulence of causal agent. Plant Disease 78:265-268.

Melgar J, Roy KW, Abney TS (1994) Sudden death syndrome of soybean: etiology, symptomatology, and effects of irrigation and Heterodera glycines on incidence and severity under field conditions. Canadian Journal of Botany 72:1647-1653.

Mueller DS, Hartman G, Nelson RL, Pedersen WL (2002) Evaluation of Glycine max germ plasm for resistance to Fusarium solani $\mathrm{f}$. sp. glycines. Plant Disease 86:741-746.

Mueller DS, Li S, Hartman G, Pedersen WL (2002) Use of aeroponic chambers and grafting to study partial resistance to Fusarium solani f. sp. glycines in soybean. Plant Disease 86:1223-1226.

Mueller DS, Nelson RL, Hartman GL, Pedersen WL (2003) Response of commercially developed soybean cultivars and the ancestral soybean lines to Fusarium solani f. sp. glycines. Plant Disease 87:827-831.

Nakajima T, Mitsueda T, Charchar MJD (1996) First occurrence of sudden death syndrome of soybean in Brazil. Japan Agricultural Research Quarterly 30:31-34.

Navi SS, Yang XB (2008) Foliar Symptom Expression in Association with Early Infection and Xylem Colonization by Fusarium virguliforme (formerly F. solani f. sp. glycines), the Causal Agent of Soybean Sudden Death Syndrome. Plant Management Network Plant Health Progress doi: 10.1094/PHP-2008-0222-01-RS.

Njiti VN, Johnson JE, Torto GA, Gray LE, Lightfoot DA (2001) Inoculum rate influences selection for field resistance to soybean sudden death syndrome in the greenhouse. Crop Science 41:17261731.

O’Donnell K, Sink S, Scandiani MM, Luque A, Colletto A, Biasoli M, Lenzi L, Salas G, González V, Ploper LD, Formento N, Pioli RN, Aoki T, Yang XB, Sarver BAJ (2010) Soybean sudden death syndrome species diversity within North and South America revealed by multilocus genotyping. Phytopathology 100:58-71.

R Development Core Team (2008) A language and environment for statistical computing. R Foundation for Statistical Computing, Vienna, Austria. ISBN 3-900051-07-0, URL.

Roy KW (1997) Sporulation of Fusarium solani f. sp. glycines, the causal agent of sudden death syndrome, on soybean plants symptomatic for the disease in the midwestern and southern United
States. Plant Disease 81:566-569.

Rupe JC (1989) Frequency and pathogenicity of Fusarium solani recovered from soybeans with sudden death syndrome. Plant Disease 73:581-584.

Rupe JC (1991) Cultivar response to sudden death syndrome of soybean. Plant Disease 75:47-50.

Rupe JC (1995) Effect of plant age, maturity group, and the environment on disease progress of sudden death syndrome of soybean. Plant Disease 79:139-143.

Rupe JC, Becton CM, Williams KJ, Yount P (1996) Isolation, identification, and evaluation of fungi for the control of sudden death syndrome of soybean. Canadian Journal of Plant Pathology 18:1-6.

Rupe JC, Correll JC, Guerber JC, Becton CM, Becton EE, Gbur EE Jr, Cummings MS, Yount PA (2001) Differentiation of the sudden death syndrome pathogen of soybean, Fusarium solani f. sp. glycines, from other isolates of $F$. solani based on cultural morphology, pathogenicity, and mitochondrial DNA restriction fragment length polymorphisms. Canadian Journal of Botany 79:829-835.

Scandiani M, Ruberti D, Pioli R, Luque A, Giorda L (2003) First report of Koch's postulates completion of sudden death syndrome of soybean in Argentina. Plant Disease 87:447.

Scandiani M, Ruberti D, O’Donnell K, Aoki T, Pioli R, Giorda L, Luque A, Biasoli M (2004) Recent oubreak of soybean sudden death syndrome caused by Fusarium virguliforme and Fusarium tucumaniae in Argentina. Plant Disease 88:1044.

Scherm H, Yang XB (1996) Development of sudden death syndrome of soybean in relation to soil temperature and soil water matric potential. Phytopathology 86:642-649.

Schuerger AC, Mitchell DJ (1993) Influence of mucilage secreted by macroconidia of Fusarium solani f. sp. phaseoli on spore attachment to roots of Vigna radiata in hydroponic nutrient solution. Phytopathology 83:1162-1170.

Schuerger AC, Mitchell DJ, Kaplan DT (1993) Influence of carbon source on attachment and germination of macroconidia of Fusarium solani $\mathrm{f}$. sp. phaseoli on roots of Vigna radiata grown in hydroponic nutrient solution. Phytopathology 83:1171-1177.

Singleton LL, Mihail JD, Rush CM (1993) Methods for research on soilborne phytopahogenic fungi. $2^{\text {nd }} \mathrm{Ed}$. American Phytopathological Society. St. Paul, MN.

Wrather JA, Kending SR, Anand SC, Niblack TL, Smith GS (1995) Effects of tillage, cultivar, and planting date on percentage of soybean leaves with symptoms of sudden death syndrome. Plant Disease 79:560-562.

Wrather JA, Anderson TR, Arsyad DM, Gai J, Ploper LD, PortaPuglia A, Ram HH, Yorinori JT (1997) Soybean disease loss estimates for the top 10 soybean producing countries in 1994. Plant Disease $81: 107-110$.

Zaccaron ML, Yang XB, Navi SS (2010) Foliar symptoms expression and early infection of soybean sudden death syndrome. Phytopathology 100:S144. 